\title{
A prospective non-randomized two-centre study of patients with passive faecal incontinence after birth trauma and patients with soiling after anal surgery, treated by elastomer implants versus rectal irrigation
}

\author{
S. J. van der Hagen - W. van der Meer • P. B. Soeters • \\ C. G. Baeten - W. G. van Gemert
}

Accepted: 13 April 2012 / Published online: 11 May 2012

(C) The Author(s) 2012. This article is published with open access at Springerlink.com

\begin{abstract}
Aim This study is a prospective evaluation of patients with passive faecal incontinence and patients with soiling treated by elastomer implants and rectal irrigation.

Patients and methods Patients with passive faecal incontinence after birth trauma resulting from a defect of the internal sphincter and patients with soiling after previous anal surgery were included. All patients underwent endoanal ultrasound, magnetic resonance imaging, and anal manometry. The patients with passive faecal incontinence were initially treated by anal sphincter exercises and biofeedback therapy during half a year. The patients completed incontinence scores, a quality of life questionnaire, and a 2-week diary card.

Results The elastomer group consisted of 30 males and 45 females with a mean age of 53 years $(25-77)$. The rectal irrigation group consisted of 32 males and 43 females with a mean age of 50 years (25-74). At 6 months follow-up, 30 patients with soiling of the rectal irrigation group and only nine patients of the elastomer group were completely cured $(p=0.02)$. Only three patients with passive faecal incontinence
\end{abstract}

\footnotetext{
S. J. van der Hagen $(\bowtie) \cdot$ P. B. Soeters • C. G. Baeten •

W. G. van Gemert

Department of Surgery, University Hospital of Maastricht,

Boerhaavestraat 1 ,

Stadskanaal 9501, HE, the Netherlands

e-mail: s.vanderhagen@refaja.nl
}

S. J. van der Hagen $\cdot$ W. van der Meer

NPBC (Nederlands Proctologisch Bekkenbodem Centrum),

Assen, the Netherlands

S. J. van der Hagen • W. van der Meer

Refaja Hospital,

Stadskanaal, the Netherlands were cured in the rectal irrigation group and none in the elastomer group. Three distal migrations of elastomer implants required removal at follow-up.

Conclusions After patients had performed anal sphincter exercises, no clear improvement of passive faecal incontinence was obtained by elastomer implants or rectal irrigation. However, rectal irrigation is far more effective than elastomer implants in patients with soiling.

Keywords Passive faecal incontinence $\cdot$ Birth trauma $\cdot$ Anal surgery $\cdot$ Elastomer implants

\section{Introduction}

Passive faecal incontinence

Passive faecal incontinence is caused by incomplete evacuation of stools and/or an insufficient anal sphincter. Some of these patients passively loose stools predominantly during walking. These faecal losses are not severe but have nevertheless a major negative impact on quality of life. Diets to solidify the faeces and sphincter exercise are frequently prescribed but do not always have satisfactory effects. The internal anal sphincter (IAS) provides most of the resting anal pressure and is the main muscle responsible for the prevention of anal leakage [1, 2]. Degeneration of the IAS is presumed to be the cause of passive faecal incontinence in the elderly [3]. Complex operations such as the dynamic graciloplasty or the newer artificial bowel sphincter provide an elevation in resting pressure. These operations are most appropriate in case of major sphincter disruption. They require considerable expertise to achieve good results and 
are associated with a relatively high complication rate [4, 5]. Most patients have only a partial defect of the internal anal sphincter. Bulking agents like elastomer implants may have beneficial effects in patients with passive faecal incontinence $[6,7]$.

\section{Soiling}

Soiling is only mentioned in papers dealing with ano-rectal diseases but never discussed on its own merit. Nevertheless, patients with soiling have "a leakage problem", which presents often after defecation, but they are most of the time continent for flatus and liquids. These patients loose "brown fluids" and suffer from anal dermatitis and itching. Anorectal manometry is within the normal range [8]. Soiling is caused by insufficient clearing of the anal canal after normal defecation. This occurs when sticky faeces stays behind in an anal canal that is anatomically disrupted. The anatomical abnormality may be present in patients with haemorrhoids or in patients who underwent anal surgery resulting in scar tissue or key-hole defects. The scar lesion (key-hole defect) is one important aspect of soiling; however, there are also patients with a key-hole defect without faecal soiling. Since there is also no effective surgical therapy for soiling, injection of bulking agents like PTQ implants may alleviate symptoms by promoting complete evacuation of faeces by restoring the anal canal $[8,9]$.

Complete evacuation of faeces by enemas or rectal irrigation after defecation appears to be an alternative in conservative treatment. This therapy is described in studies for soiling and retentive encopresis in children $[10,11]$. Gosselink et al. [12] reported beneficial effects of retrograde colonic irrigation in patients with bowel disorders and faecal incontinence and soiling.

Study design

In a prospective non-randomized two-centre study we compared the effectiveness of elastomer Implants or rectal irrigation with $500 \mathrm{ml}$ water after defecation in a group of patients with soiling and another group with (true) passive faecal incontinence due to a defect of the internal sphincter after birth trauma.

\section{Patients and methods}

Between January 2007 and August 2009, 150 patients with faecal soiling or passive faecal incontinence were recruited in two clinical centres. In both centres, the same scoring system and work-up was used for soiling and faecal incontinence by a multidisciplinary pelvic floor team. In one clinical centre, the physician assistant is experienced in the treatment by elastomer implants and in the other centre by rectal and colonic irrigation. The study protocol was approved by the ethical committee. Written informed consent was obtained before entering the study.

Patients with passive faecal incontinence

Female patients with passive faecal incontinence after birth trauma were included. For inclusion and exclusion criteria, see Table 1. A defect of at least the internal sphincter was confirmed by endo-anal ultrasound and MRI. A dynamic MRI was performed to exclude rectal prolapse and rectoceles. Patients completed the Cleveland Clinic FloridaFaecal Incontinence score (CCF-FI) and the faecal incontinence quality of life score (FIQL). They were initially treated in both centres by anal sphincter exercises and biofeedback therapy by a certified pelvic floor physiologist during half a year. After this training, all patients with a Cleveland Clinic Florida-Faecal Incontinence score $(\mathrm{CCF}-\mathrm{FI}) \leq 8$ were examined for the purpose of this study.

Patients with soiling

Patients with soiling after previous anal surgery were examined for the purpose of this study. Patients suffering from itching and fluid loss with or without perianal dermatitis (local reaction and irritation of the dermis) and no true passive faecal incontinence were included. For inclusion and exclusion criteria, see Table 2. They underwent an endo-anal ultrasound examination and static MRI scanning to exclude lesions of the external sphincter. Anal manometry

Table 1 Patients with passive faecal incontinence

Inclusion criteria

Birth-trauma in history

Passive faecal incontinence

$(\mathrm{CCF}-\mathrm{FI}) \leq 8$ after anal sphincter exercises and biofeedback therapy

Defect of the IAS

Exclusion criteria

Immunosuppression

Prior elastomer implants

Defect of the pudendal nerve

Inflammatory bowel disease

Spinal cord injury

Acute inflammation, infection, malignancy, or post radiation

Current pregnancy or planned further vaginal deliveries

Rectal prolapse

Rectocele $>1 \mathrm{~cm}$

Low anterior resection

Age younger than 18 
Table 2 Patients with faecal soiling

Inclusion criteria

Soiling:

Itching and

Fluid loss and/or

Perianal dermatitis (a local reaction at the anodermal skin resulting in itching)

The results of anal manometry within the normal range

Anal surgery in history

Exclusion criteria

Associated external sphincter defect

Immunosuppression

Haemorrhoids grade IV

Faecal incontinence

Inflammatory bowel disease

Current pregnancy or planned further vaginal deliveries

Rectal prolapse

Rectocele $>1 \mathrm{~cm}$

Low anterior resection

Acute inflammation, infection, malignancy, or post-radiation

Age younger than 18

(a polygraph; Medical Synectics, Stockholm) had to be within the normal range (resting pressure, $>40 \mathrm{mmHg} / \mathrm{max}-$ imum squeeze pressure, $>75 \mathrm{~mm} \mathrm{Hg}$ ). Patients with faecal soiling completed the Vaizey incontinence score, KEA quality of life questionnaire score (an EuroQol-5D instrument for faecal incontinence [13]), and a 2-week diary card. The Vaizey incontinence and KEA quality of life score was added because soiling is an important variable in this score system in contrast to the CCF-FI and FIQL [13].

\section{Elastomer implants}

Between January 2007 and August 2009, all consecutive patients of one centre with faecal soiling and passive faecal incontinence were offered treatment by elastomer (PTQ ${ }^{\mathrm{TM}}$ ) implants. Written informed consent was obtained before starting therapy. PTQ Implants (formerly called Bioplastique $^{\mathrm{TM}}$ ) are solid, irregularly textured, medical grade polydimethylsiloxane elastomer implants suspended in a hydrogel carrier of polyvinylpyrrolidone (PVP or povidone). Injections were performed on an outpatient basis under local anaesthesia. A combination of xylocaine $1 \%$ and marcaine $0.25 \%$ was infiltrated into the skin over the proposed site of injection with the cutaneous entry site $>2 \mathrm{~cm}$ lateral to the sphincter complex and into the deeper soft tissue structures. Patients were injected in the supine or back position. Injecting needle tips were positioned into the submucosal internal sphincter interface under guidance of a palpating finger. Three $2.5 \mathrm{ml}$ injections were placed at 3, 7, and 11 o'clock in supine position. All procedures were performed under protection of a prophylactic single dose of intravenous metronidazole $500 \mathrm{mg}$ and cefuroxime $1,500 \mathrm{mg}$. Postoperatively oral antibiotics were continued for 5 days (amoxicillin/clavulane acid $625 \mathrm{mg}$ three times daily) [8]. In the event of treatment failure or partial improvement requiring further elastomer implantations, the re-implantation was not carried out until 4 weeks after the initial procedure.

Adverse effects were defined as moderate (superficial temporary infections) and severe (abscesses needing drainage procedures and removal of the implant).

\section{Rectal irrigation}

In the other centre between January 2007 and April 2009, all consecutive patients with faecal soiling and passive faecal incontinence were offered treatment by rectal irrigation. The nurse practitioner specialized in treatment of faecal incontinence explained the use of $500 \mathrm{ml}$ of water containing bottles $\left(\right.$ REPROP $\left.^{\circledR}\right)$ for irrigation and trained the patients in using it. Irrigation had to be performed after defecation.

The Cleveland Clinic Florida-Faecal Incontinence score (CCF-FI) and the faecal incontinence quality of life score (FIQL) were repeated 6 months after starting treatment.

\section{Statistical analysis}

At baseline and at 6 months, comparisons between elastomer group and rectal irrigation group were performed with $t$ test (or Wilcoxon test as appropriate) for continuous variable and chi-squared test for categorical variables (or Fisher's exact test as appropriate). A $p$ value of $<0.05$ was considered significant.

\section{Results}

Patients with faecal incontinence

Between January 2007 and August 2009, 70 female patients with a mean age of 54 years (range 32-77) with faecal incontinence were included (flowchart, Fig. 1; the patient characteristics and outcome are described in Table 3). All patients returned for follow-up at 6 months. Defects of the internal anal sphincter were observed in $49(70 \%)$ patients. Degeneration of the internal anal sphincter (mean width $<2 \mathrm{~mm}$ ) was noted in $52(75 \%)$ patients. In 45 (64\%) patients, a defect of the external sphincter was found on MRI. 
Fig. 1 Flow chart of patients with faecal incontinence

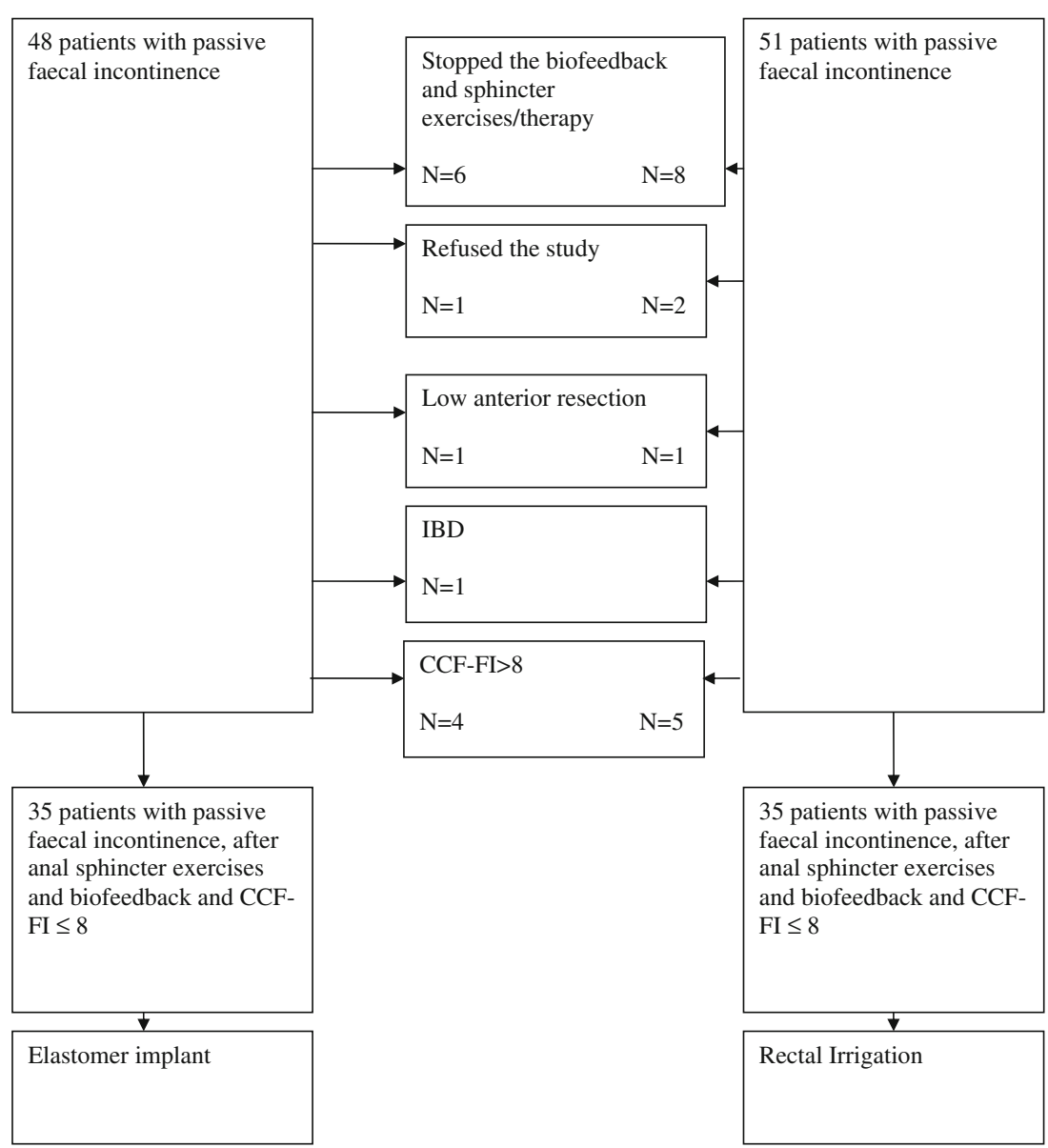

Table 3 Patients characteristics and outcome; patients with passive faecal incontinence

\begin{tabular}{|c|c|c|c|c|c|c|}
\hline & \multicolumn{2}{|c|}{ Elastomer group $N=35$} & \multicolumn{2}{|c|}{ Rectal irrigation group $N=35$} & \multicolumn{2}{|c|}{ Statistical analysis } \\
\hline & Baseline & At 6 months & Baseline & At 6 months & Baseline & At 6 months \\
\hline Age & $55(32-77)$ & & $53(38-74)$ & & ns & \\
\hline \multicolumn{7}{|l|}{ Patient history: } \\
\hline $\operatorname{Sex}(M: F)$ & $0: 35$ & & $0: 35$ & & & \\
\hline Defects of the external anal sphincter & $20(57 \%)$ & & $25(71 \%)$ & & ns & \\
\hline \multicolumn{7}{|l|}{ Anal manometry: } \\
\hline Maximum basal pressure (mmHg) & $39(25-51)$ & & $41(29-44)$ & & ns & \\
\hline Maximum squeeze pressure (mmHg) & $69(57-131)$ & & $79(51-144)$ & & ns & \\
\hline CCIS-FI & $6.2(4-8)$ & $5.8(5-8)$ & $6.4(4-8)$ & $6.2(0-8)$ & ns & ns \\
\hline \multicolumn{7}{|l|}{ FIQL: } \\
\hline Lifestyle & $4,5(3-8)$ & 4.7 & 4.9 & 5.0 & ns & ns \\
\hline Coping behaviour & $5.3(3-8)$ & 5.7 & 4.5 & 4.0 & ns & ns \\
\hline Depression/self-perception & $3.9(1-6)$ & 4.1 & 3.8 & 4.0 & ns & ns \\
\hline Embarrassment & $2.1(1-3)$ & 1.9 & 2.0 & 2.0 & ns & ns \\
\hline \multicolumn{7}{|l|}{ Faecal incontinence: } \\
\hline Solid stools (days/week) average & $2.2(0-5)$ & $1.7(0-3)$ & $2.0(0-4)$ & $1.9(0-3)$ & ns & ns \\
\hline Liquid stools (days/week) average & $1.2(1-7)$ & $0.9(0-3)$ & $2.0(1-7)$ & $1.8(0-3)$ & ns & ns \\
\hline Pads for faecal incontinence Average number/day & $0.8(0-3)$ & $0.9(0-4)$ & $1.0(0-3)$ & $0.9(0-4)$ & ns & ns \\
\hline
\end{tabular}


In the elastomer group, in no patient faecal incontinence resolved completely. In the rectal irrigation group, faecal incontinence resolved completely in $3(9 \%)$ patients. The CCIS-FI score, the average number of days/week of incontinence for solid or liquid stools and the average number of pads used daily did not change significantly after treatment in and between groups. Similarly, no improvement was found in the mean faecal incontinence quality of life score for both groups after 6 months follow-up.

There were no severe adverse effects. In the elastomer group, two infections were observed at follow-up shortly after treatment. Two patients with treatment failure received a second elastomer implant. The implants appeared to be placed subdermally instead of intersphincterically.

In two patients, distal migration of an implant occurred, requiring removal of the implant under spinal anaesthesia after 14 and 18 months of follow-up.

\section{Patients with soiling}

Between January 2007 and August 2009, 80 patients with a median age of 51 years (range 25-79) with faecal soiling were included (flowchart, Fig. 2; the patient characteristics and outcome are described in Table 4). In the rectal irrigation group, three patients discontinued therapy during follow-up.

The mean basal pressure and the mean squeeze pressure at anal manometry were within the normal range; 66 (4092) and 168 (75-202) $\mathrm{mmHg}$, respectively.

In the elastomer group, the soiling complaints resolved completely in $9(23 \%)$ and in the rectal irrigation group 30 $(75 \%)$ patients $(p=0.02)$.

The average soiling frequency, the number of patients wearing pads daily and the mean Vaizey incontinence score diminished significantly in the rectal irrigation group compared to the elastomer group after treatment. The mean KEA quality of life questionnaire score for faecal incontinence after treatment improved significantly in the rectal irrigation group compared to the elastomer group.

Endosonography revealed defects of the internal anal sphincter in $54(68 \%)$ patients. Degeneration of the internal anal sphincter (mean width $<2 \mathrm{~mm}$ ) was noted in $63(76 \%)$ patients.

There were no severe adverse effects. In the elastomer group, one infection was observed post-treatment at short time follow-up. Two patients received a second elastomer
Fig. 2 Flow chart of patients with faecal soiling

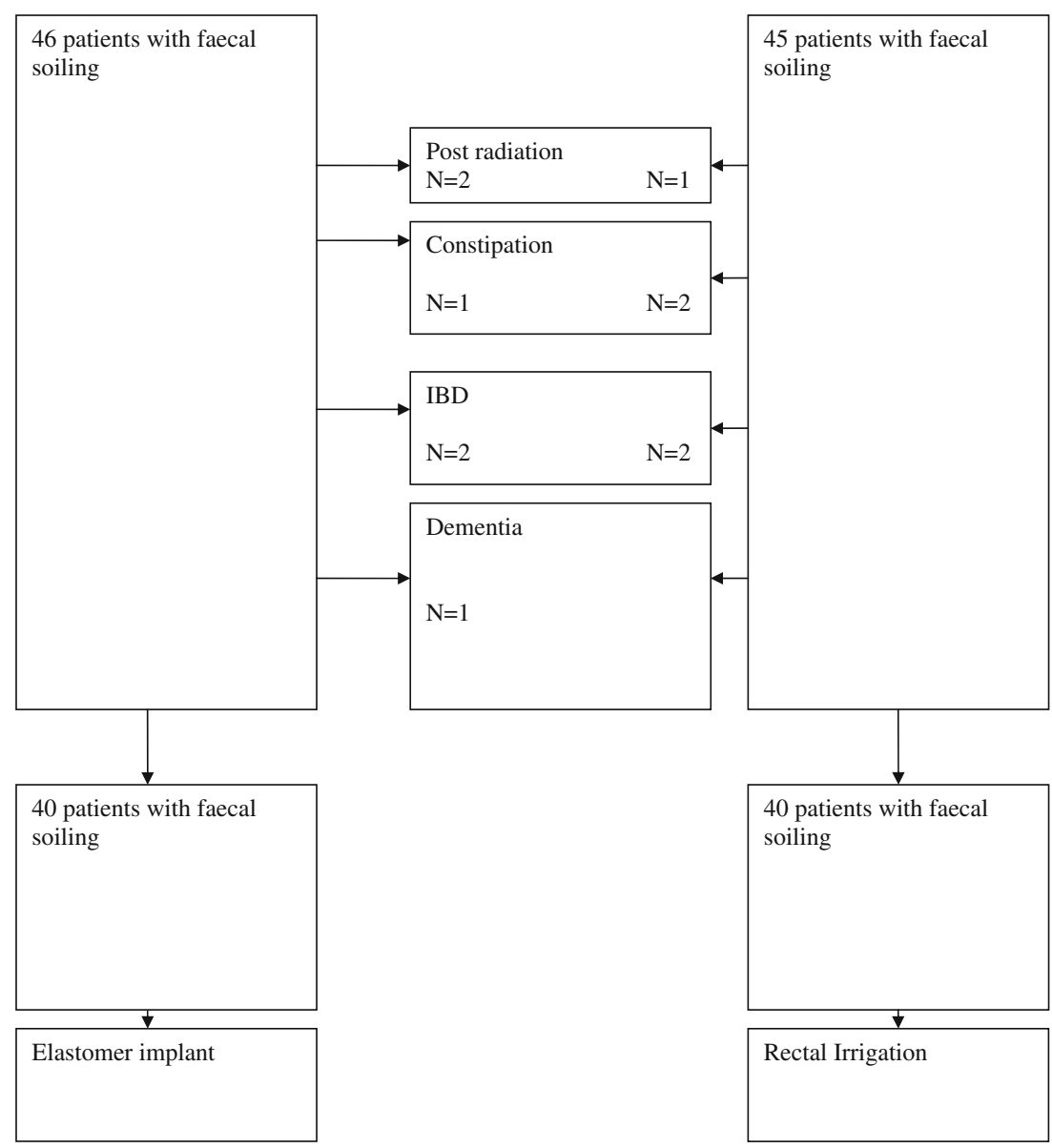


Table 4 Patients characteristics and outcome; patients with faecal soiling

\begin{tabular}{|c|c|c|c|c|c|c|}
\hline & \multicolumn{2}{|c|}{ Elastomer group } & \multicolumn{2}{|c|}{ Rectal irrigation group } & \multicolumn{2}{|c|}{ Statistical analysis } \\
\hline & $\begin{array}{l}N=40 \\
\text { Baseline }\end{array}$ & $\begin{array}{l}N=40 \\
\text { At } 6 \text { months }\end{array}$ & $\begin{array}{l}N=40 \\
\text { Baseline }\end{array}$ & $\begin{array}{l}N=37 \\
\text { At } 6 \text { months }\end{array}$ & Baseline & $\begin{array}{l}N=37 \\
\text { At } 6 \text { months }\end{array}$ \\
\hline Age & $51(28-75)$ & & $48(25-79)$ & & ns & \\
\hline $\operatorname{Sex}(M: F)$ & $30: 10$ & & $32: 8$ & & ns & \\
\hline \multicolumn{7}{|l|}{ Patient history } \\
\hline Haemorrhoidectomy & 27 & & 28 & & ns & \\
\hline Fistula surgery & 6 & & 8 & & ns & \\
\hline Other anal surgery & 7 & & 4 & & ns & \\
\hline Defects of the internal anal sphincter & $26(65 \%)$ & & $28(70 \%)$ & & ns & \\
\hline Degeneration of the internal anal sphincter & $33(83 \%)$ & & $30(75 \%)$ & & ns & \\
\hline \multicolumn{7}{|l|}{ Anal manometry } \\
\hline Maximum basal pressure $(\mathrm{mmHg})$ & $67(42-86)$ & & $64(40-92)$ & & ns & \\
\hline Maximum squeeze pressure (mmHg) & $161(202-79)$ & & $174(200-75)$ & & ns & \\
\hline \multicolumn{7}{|l|}{ Outcome } \\
\hline Patients discontinued therapy & & 0 & & 3 & & \\
\hline Complete response & & $9(23 \%)$ & & $30(75 \%)$ & & 0.02 \\
\hline Average daily soiling frequency & $2.0(1-5)$ & $2.1(0-5)$ & $2.0(1-7)$ & $0.4(0-2)$ & ns & 0.0001 \\
\hline The average soiling day-time frequency & $0.5(0-1)$ & $0.3(0-1)$ & $1.3(0-2)$ & $0.45(0-2)$ & ns & 0.001 \\
\hline The average soiling night-time frequency & $0.2(0-1)$ & $0.2(0-2)$ & $0.7(0-1)$ & $0.03(0-1)$ & 0.06 & 0.001 \\
\hline The average soiling after stool frequency & $2.2(0-6)$ & $0.5(0-2)$ & $2.2(0-7)$ & $0.3(0-1)$ & ns & 0.001 \\
\hline Patients wearing pads daily & $32(80 \%)$ & $20(50 \%)$ & $30(75 \%)$ & $7(18 \%)$ & ns & 0.001 \\
\hline The mean Vaizey-incontinence score & $4.2(0-8)$ & $2.5(0-6)$ & $4.2(2-9)$ & $0.9(0-5)$ & ns & 0.0001 \\
\hline $\begin{array}{l}\text { The mean KEA quality of life } \\
\text { questionnaire score for faecal incontinence }\end{array}$ & $83(54-100)$ & $82(49-97)$ & $81(53-100)$ & $93(75-100)$ & $\mathrm{ns}$ & 0.0001 \\
\hline
\end{tabular}

implant because of insufficient bulking at the site of the anal cushions. In one patient, distal migration of an implant occurred that had to be removed under spinal anaesthesia after 20 months follow-up.

\section{Discussion}

Faecal incontinence is a socially and psychologically distressing condition that affects many people. In the United States, 1 in 10 women has faecal incontinence, with 1 in 15 having moderate to severe faecal incontinence [14]. However, approximately $70 \%$ of patients with faecal incontinence do not consult a physician [15]. Therefore, the true prevalence of faecal incontinence and soiling remains unknown and is hard to establish because of underreporting of symptoms by patients, differences in data collection, and different standardized scoring scales [16]. In this study, 16 male patients had soiling complaints for more than 10 years.

There is no established effective therapy for soiling. Mostly, soiling is present in patients having semi-solid faeces, and dietary measures to thicken the faeces is therefore frequently prescribed. In most patients, this therapy is not effective. Patients with a clinical relevant rectocele and prolapse were excluded because the mechanisms underlying faecal incontinence and soiling are different, requiring different therapeutic approaches.

Colorectal surgeons are preferentially applying conservative or minimally invasive treatment for patients with mild passive faecal incontinence and for patients with soiling. The first report of beneficial effects of implanted bulking agents was published in 1993 by Shafik [17]. Several reports followed describing a variable benefit of the use of elastomer implants [6-9, 18-21]. A study in 2007 showed that restoration of the anal canal by elastomer implants also appeared to diminish soiling complaints [8].

The internal anal sphincter (IAS) provides most of the resting anal pressure $[22,23]$ and is presumed to be the main muscle responsible for the prevention of passive faecal incontinence. Vascular filling in the anal cushions contributes approximately $15-20 \%$ of the resting anal canal pressure [24]. The anal cushions act as a "compliant and comfortable plug" at the anal margin [25]. In contradistinction with passive faecal incontinence, the function and 
interaction of the anal cushions and the internal sphincter in soiling is still not clear. Anal dysfunction is not the cause of anal soiling. Hoffman et al. [26] found that the mechanism of incontinence in patients with soiling is different from the patients with moderate and severe faecal incontinence in an anal manometric study performed in 170 patients. Felt-Bersma et al. [27] did not find any difference in anorectal function tests between patients with soiling (without faecal incontinence) and the control group, except for the patients with a rectal prolapse. In the present study and a previous study [8], the resting and squeeze pressures of the anal canal in patients with soiling were within the normal range (Table 4).

In our study as well as in other studies, a maximum of $2.5 \mathrm{ml}$ of the elastomer implants ( $7.5 \mathrm{ml}$ total volume) was used at the sites of the three haemorrhoidal cushions [7, 19]. There are some encouraging earlier studies regarding the treatment of faecal incontinence by intersphincteric elastomer injections $[6,7,9,19,21,28,29]$. The negative result observed in the present study does not appear to rely on inadequate selection criteria of our patients. All subjects studied had passive faecal incontinence, a CCIS score $<8$ and none of the patients had a rectocele or an internal or external prolapse. A similar method as in the earlier studies was used to inject the elastomer implants. The elastomer biomaterial was positioned into the intersphincteric space through the anal skin and the external anal sphincter. Tjandra was the first who reported that using ultrasound guidance during injection might lead to better functional results [30]. Maeda et al. reported in a Cochrane review some short-term benefits of ultrasound guidance [31]. But there is still no evidence that ultrasound guidance leads to better outcome. We are familiar with the strategy of the guiding finger. Although impossible to prove on the basis of the present data, we think it is unlikely that the use of the guiding finger instead of guidance by ultrasound is responsible for the disappointing results in this study.

Our results are in agreement however with the study of Siproudhis et al. [32] who in a randomized study could not demonstrate a benefit of intersphincteric elastomer injected by guidance of the finger in the treatment of patients with moderate to severe faecal incontinence. They suggested that the implants might have more benefit in mild faecal incontinence. Soerensen et al. [29] concluded that the benefit of elastomer implants is limited to minor leakage and soiling in a prospective study of 33 patients. In our study, only patients with mild faecal incontinence (Cleveland Clinic Florida-Faecal Incontinence score $(\mathrm{CCF}-\mathrm{FI}) \leq 8)$ after birth trauma and without clinical relevant rectoceles and prolapse were included and nevertheless disappointing results were achieved.

Maeda et al. [31] found no objective clinical benefit of bulking agents in patients with fecal incontinence and indicated the necessity of large well-designed trails. Recently, a prospective sham-controlled trial of 206 patients with a variable severity of fecal incontinence was published. The bulking agent dextranomer in stabilised hyaluronic acid was injected and showed in $52 \%$ of the patients a reduction of $50 \%$ or more in incontinence episodes compared to $31 \%$ of the patients with the sham treatment [33]. The authors concluded that the injection of this substance was an effective treatment for faecal incontinence. However, no information was provided regarding the type of incontinence.

No clear benefit of treatment with elastomer implants is demonstrated in the present patient group with passive faecal incontinence after biofeedback therapy and sphincter exercise. Bartlett and $\mathrm{Ho}$ [34] reported a prospective study and found that patients who had previously received biofeedback treatment had the poorest results after elastomer implants. No information has been provided regarding the influence of previously received biofeedback treatment and anal sphincter exercise in the other studies.

Antegrade and retrograde colonic irrigation and rectal irrigation are widely used for functional bowel disorders and soiling $[11,12,35]$. This therapy appears to be effective in patients with faecal incontinence and soiling as a result of functional bowel disorders like constipation or a medical history like Hirschsprung's disease or rectal prolapse. The water removes the remaining faeces in the colon and/or rectum. The present study shows that irrigation of the anal canal in patients with soiling after anal surgery without functional bowel disorders or rectal prolapse is a very effective and simple treatment modality. Minor forms of evacuation like suppositories seem to offer a more convenient way of treatment. There are no data in the literature to prove this. Nevertheless, we expect that complete cleaning of the rectum is responsible for the good results [36]. The long term therapeutic benefit depends on the severity of soiling complaints on the one hand and the therapeutic compliance of the patient on the other hand.

Rectal irrigation is not sufficiently effective in patients with passive faecal incontinence and an anal sphincter defect. Probably, such patients need colonic irrigation to ensure that a larger part of the colon is irrigated.

We can conclude that in this well-selected group of patients, no clear benefit could be demonstrated from elastomer implants or rectal irrigation in patients with mild faecal incontinence after biofeedback therapy and sphincter exercises. But in the group of patients with soiling, rectal irrigation is effective and superior to elastomer implants. The present study confirms the safety of elastomer implants reported in other studies [37].

Open Access This article is distributed under the terms of the Creative Commons Attribution License which permits any use, distribution, and reproduction in any medium, provided the original author(s) and the source are credited.

\section{References}

1. Frenckner B (1976) Function of the anal sphincters in spinal man. Gut 16(8):638-644 
2. Duthie HL, Watts JM (1965) Contribution of the external anal sphincter to the pressure zone in the anal canal. Gut 6:64-68

3. Vaizey CJ, Kamm MA, Bartram CI (1997) Primary degeneration of the internal anal sphincter as a cause of passive faecal incontinence. Lancet 349(9052):612-615

4. Sielezneff I, Malouf AJ, Bartolo DC et al (1999) Dynamic graciloplasty in the treatment of patients with faecal incontinence. $\mathrm{Br} \mathrm{J}$ Surg 86(1):61-65

5. Geerdes BP, Heineman E, Konsten J et al (1996) Dynamic graciloplasty. Complications and management. Dis Colon Rectum 39 (8):912-917

6. Chan MK, Tjandra JJ (2006) Injectable silicone biomaterial (PTQ) to treat fecal incontinence after hemorrhoidectomy. Dis Colon Rectum 49(4):433-439

7. de la Portilla F, Fernandez A, Leon E et al (2008) Evaluation of the use of PTQ implants for the treatment of incontinent patients due to internal anal sphincter dysfunction. Colorectal Dis 10(1):89-94

8. van der Hagen SJ, van Gemert WG, Baeten CG (2007) PTQ Implants in the treatment of faecal soiling. Br J Surg 94(2):222223

9. Oliveira LC, Neves Jorges JM, Yussuf S et al (2009) Anal incontinence improvement after silicone injection may be related to restoration of sphincter asymmetry. Surg Innov 16(2):155-161

10. Stark LJ, Owens-Stively J, Spirito A et al (1990) Group behavioural treatment of retentive encopresis. J Pediatr Psychol 15 (5):659-671

11. Katz C, Drongowski RA, Coran AG (1987) Long-term management of chronic constipation in children. J Pediatr Surg 22(10):976978

12. Gosselink MP, Darby M, Zimmerman DD et al (2005) Long-term follow-up of retrograde colonic irrigation for defaecation disturbances. Colorectal Dis 7(1):65-69

13. Deutekom M, Terra MP, Dobben AC et al (2005) Impact of faecal incontinence severity on health domains. Colorectal Dis 7(3):263269

14. Bharucha AE, Zinsmeister AR, Locke GR et al (2005) Prevalence and burden of fecal incontinence: a population-based study in women. Gastroenterology 129(1):42-49

15. Johanson JF, Lafferty J (1996) Epidemiology of fecal incontinence: the silent affliction. Am J Gastroenterol 91(1):33-36

16. Madoff RD, Parker SC, Varma MJ, Lowry AC (2004) Faecal incontinence in adults. Lancet 364(9434):621-632

17. Shafik A (1993) Polytetrafluoroethylene injection for the treatment of partial fecal incontinence. Int Surg 78(2):159-161

18. Davis K, Kumar D, Poloniecki J (2003) Preliminary evaluation of an injectable anal sphincter bulking agent (Durasphere) in the management of faecal incontinence. Aliment Pharmacol Ther 18 (2):237-243

19. Kenefick NJ, Vaizey CJ, Malouf AJ et al (2002) Injectable silicone biomaterial for faecal incontinence due to internal anal sphincter dysfunction. Gut 51(2):225-228
20. Maeda Y, Vaizey CJ, Kamm MA (2007) Long-term results of perianal silicone injection for faecal incontinence. Colorectal Dis 9(4):357-361

21. Malouf AJ, Vaizey CJ, Norton CS, Kamm MA (2011) Internal anal sphincter augmentation for fecal incontinence using injectable silicone biomaterial. Dis Colon Rectum 44(4):595-600

22. Frenckner B, Euler CV (1975) Influence of pudendal block on the function of the anal sphincters. Gut 16(6):482-489

23. Duthie HL, Watts JM (1965) Contribution of the external anal sphincter to the pressure zone in the anal canal. Gut 6:64-68

24. Lestar B, Penninckx F, Kerremans R (1989) The composition of anal basal pressure. An in vivo and in vitro study in man. Int J Colorectal Dis 4(2):118-122

25. Loder PB, Kamm MA, Nicholls RJ, Phillips RK (1994) Haemorrhoids: pathology, pathophysiology and aetiology. Br J Surg 81 (7):946-954

26. Hoffmann BA, TimmckeAE GJB Jr et al (1995) Fecal seepage and soiling: a problem of rectal sensation. Dis Colon Rectum 38(7):746748

27. Felt-Bersma RJ, Janssen JJ, Klinkenberg-Knol EC et al (1989) Soiling: anorectal function and results of treatment. Int J Colorectal Dis 4(1):37-40

28. Vaizey CJ, Kamm MA (2005) Injectable bulking agents for treating faecal incontinence. Br J Surg 92(5):521-527

29. Soerensen MM, Lundby L, Buntzen S, Laurberg S (2009) Intersphincteric injected silicone biomaterial implants: a treatment for faecal incontinence. Colorectal Dis 11(1):73-76

30. Tjandra JJ, Lim JF, Hiscock R, Rajendra P (2004) Injectable silicone biomaterial for fecal incontinence caused by internal anal sphincter dysfunction is effective. Dis Colon Rectum 47(12):21382146

31. Maeda Y, Laurberg S, Norton C (2010) Perianal injectable bulking agents as treatment for faecal incontinence in adults. Cochrane Database Syst Rev, (5): p. CD007959

32. Siproudhis L, Morcet J, Laine F (2007) Elastomer implants in faecal incontinence: a blind, randomized placebo-controlled study. Aliment Pharmacol Ther 25(9):1125-1132

33. Graf W, Mellgren A, Matzel KE et al (2011) Efficacy of dextranomer in stabilised hyaluronic acid for treatment of faecal incontinence: a randomised, sham-controlled trial. Lancet 377(9770):9971003

34. Bartlett L, Ho YH (2009) PTQ anal implants for the treatment of faecal incontinence. Br J Surg 96(12):1468-1475

35. Tod AM, Stringer E, Levery C et al (2007) Rectal irrigation in the management of functional bowel disorders: a review. Br J Nurs 16 (14):858-864

36. van der Hagen SJ, Soeters PB, Baeten CG, van Gemert WG (2011) Conservative treatment of patients with faecal soiling. Tech Coloproctol 15(3):291-295

37. Lightner DJ (2002) Review of the available urethral bulking agents. Curr Opin Urol 12(4):333-338 